\title{
Photochemistry of HOSO radical in the gas phase
}

Cite as: J. Chem. Phys. 151, 111103 (2019); https://doi.org/10.1063/1.5119704

Submitted: 12 July 2019 . Accepted: 21 August 2019 . Published Online: 18 September 2019

Tarek Trabelsi (D), Josep M. Anglada (D), Manuel F. Ruiz-López (D), and Joseph S. Francisco (iD)

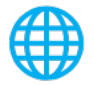

\section{ARTICLES YOU MAY BE INTERESTED IN}

In search of Coulson's lost theorem

The Journal of Chemical Physics 151, 151101 (2019); https://doi.org/10.1063/1.5128624

Resolution-of-the-identity approximation for complex-scaled basis functions

The Journal of Chemical Physics 151, 111101 (2019); https://doi.org/10.1063/1.5119695

Adventures in DFT by a wavefunction theorist

The Journal of Chemical Physics 151, 160901 (2019); https://doi.org/10.1063/1.5116338

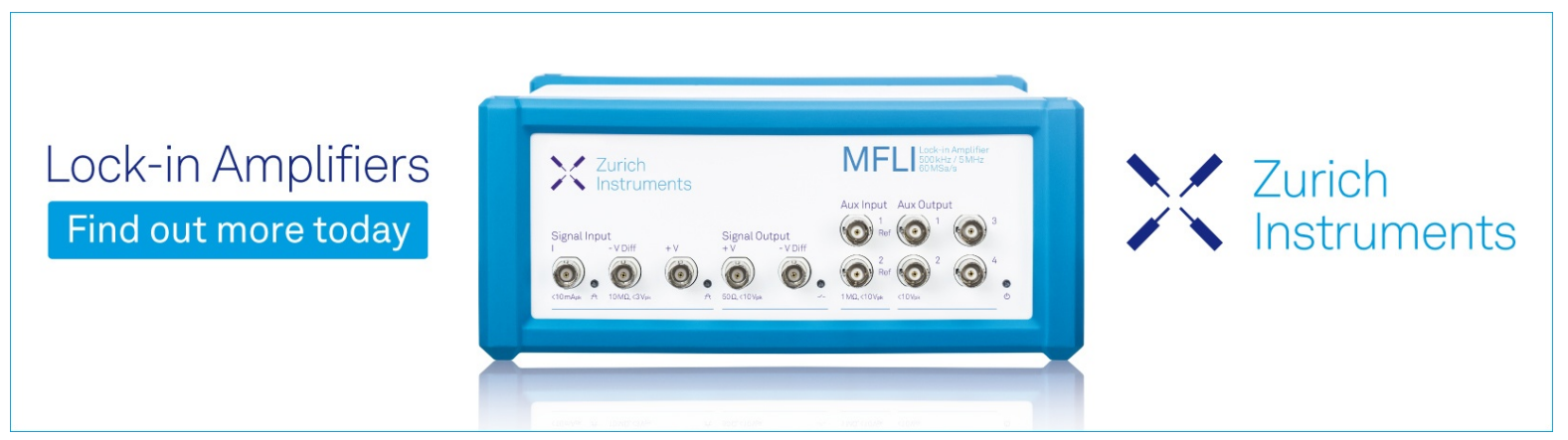




\title{
Photochemistry of HOSO radical in the gas phase
}

\author{
Cite as: J. Chem. Phys. 151, 111103 (2019); doi: 10.1063/1.5119704 \\ Submitted: 12 July 2019 Accepted: 21 August 2019 • \\ Published Online: 18 September 2019
}

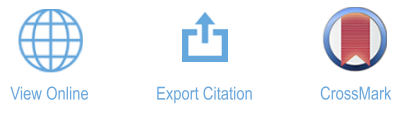

Tarek Trabelsi,' (D) Josep M. Anglada, ${ }^{2}$ (D) Manuel F. Ruiz-López, ${ }^{3}$ (D) and Joseph S. Francisco ${ }^{1, a)}$ (iD

\author{
AFFILIATIONS \\ ${ }^{1}$ Department of Earth and Environment Science, University of Pennsylvania, Philadelphia, Pennsylvania 19104-6243, USA \\ ${ }^{2}$ Departament de Química Biològica (IQAC - CSIC), c/Jordi Girona 18, E-08034 Barcelona, Spain \\ ${ }^{3}$ Laboratoire de Physique et Chimie Théoriques, UMR CNRS 7019, University of Lorraine, CNRS, BP 70239, 54506 \\ Vandoeuvre-lès-Nancy, France
}

a) Author to whom correspondence should be addressed: frjoseph@sas.upenn.edu

\begin{abstract}
The photochemistry of HOSO in the near- and deep-UV spectral range has been studied in the gas phase using the multireference configuration interaction $\mathrm{MRCI}+\mathrm{Q} / \mathrm{aug}-\mathrm{cc}-\mathrm{pV}(\mathrm{T}+\mathrm{d}) \mathrm{Z}$ level of theory. $\mathrm{HOSO}$ is found to be a nonplanar radical in its ground electronic state with a torsion angle calculated to be $49.7^{\circ}$. The lowest three doublet electronic states are characterized by a large transition dipole moment and are implicated in the photodissociation of HOSO in the gas phase to generate $\mathrm{SO}$ and $\mathrm{OH}$ as products. Sulfur dioxide and hydrogen products may also result after UV absorption to reach the first excited state, and this channel competes with the production of $\mathrm{OH}$ and $\mathrm{SO}$.
\end{abstract}

Published under license by AIP Publishing. https://doi.org/10.1063/1.5119704

Sulfur dioxide $\left(\mathrm{SO}_{2}\right)$ is a pollutant gas with both natural and industrial sources, such as fossil fuel combustion from power plants and volcano eruptions. ${ }^{2}$ Its related species, such as $\mathrm{H}_{2} \mathrm{SO}_{4}, \mathrm{HSO}_{4}$, and $\mathrm{SO}_{4}{ }^{2-}$, are of considerable interest due to their abundance and role in sulfur chemistry in the Earth's atmosphere. ${ }^{3,4}$ Due to its atmospheric implications, the interactions between sulfur dioxide and water in the gas phase and aqueous aerosols have been studied theoretically ${ }^{5-7}$ and experimentally. ${ }^{8,9}$ Recent studies show that $\mathrm{HOSO}$ and $\mathrm{OH}$ radicals may be produced through the reaction of $\mathrm{H}_{2} \mathrm{O}$ and excited $\mathrm{SO}_{2}$ [Eqs. (1) and (2)],

$$
\begin{gathered}
\mathrm{SO}_{2}+\mathrm{hv} \rightarrow{ }^{3} \mathrm{SO}_{2}, \\
{ }^{3} \mathrm{SO}_{2}+\mathrm{H}_{2} \mathrm{O} \rightarrow \mathrm{HOSO}+\mathrm{OH} .
\end{gathered}
$$

The hydroxysulfinyl radical, HOSO, can also be formed via the oxidation of $\mathrm{SO}$ by $\mathrm{OH}$ radicals ${ }^{12}$ or by recombination of $\mathrm{SO}_{2}$ with hydrogen.

Numerous theoretical works have examined HOSO in its electronic ground state; ${ }^{14-18}$ see recent theoretical ${ }^{19,20}$ and experimen$\mathrm{tal}^{21}$ papers. Some of these studies show discrepancies regarding the ground state structure of HOSO, namely, planar or nonplanar. A theoretical investigation using coupled cluster methods by Wheeler et al..$^{20}$ showed that HOSO is a nonplanar structure with a torsion angle of $24.2^{\circ}$. From an experimental point of view, the planarity problem is still unresolved, ${ }^{21}$ but all other coordinates have been measured.

The HOSO radical is an important intermediate in the Earth's atmosphere since it is involved in the atmospheric oxidation of $\mathrm{SO}_{2} \cdot{ }^{10,11}$ Its photochemistry and the stability of its excited states are unknown. To our knowledge, the photochemistry of $\mathrm{HSO}_{2}$ has been studied by Fourier-transform infrared spectroscopy (FTIR) in argon, krypton, and xenon solids. ${ }^{22}$ In that work, the authors show that the photoexcitation of $\mathrm{HSO}_{2}$ at wavelengths below $580 \mathrm{~nm}$ promotes $\mathrm{HSO}_{2} \rightarrow$ cis-HOSO interconversion and that the photodissociation threshold of cis-HOSO to $\mathrm{H}+\mathrm{SO}_{2}$ is at $400 \mathrm{~nm}$. As a result, no electronic spectroscopic data exist that can be utilized to help understanding the photomechanism and role of HOSO in the Earth's atmosphere. However, modern quantum chemical methods are capable of producing accurate data and predicting all plausible mechanisms that can occur in the gas phase. $^{23,}$

In the present communication, we use multireference configuration interaction (MRCI) methods to develop plausible photomechanisms that can occur for HOSO in the gas phase. ${ }^{23,24}$ More specifically, we map the $3 \mathrm{D}$ potential energy surface (3D-PESs) of the lowest-lying electronic state of HOSO along the stretching and bending coordinates. These PESs, together with the transition dipole moments, are used to examine the photochemistry of HOSO and 
to understand the processes that can occur after Ultraviolet Visible (UV-Vis) absorption.

To provide detailed insight into the ground and the lowest excited states of HOSO, we used the complete active space selfconsistent field (CASSCF) ${ }^{25,26}$ followed by the internally contracted multireference configuration interaction including the Davidson correction $\mathrm{MRCI}+\mathrm{Q} .{ }^{27-29}$ In these calculations, the hydrogen and oxygen atoms are described using the aug-cc-pVTZ basis set ${ }^{30}$ and the basis sets containing an extra d-function aug-cc-pV(T+d) $\mathrm{Z}^{31}$ to describe the sulfur atom. In the CASSCF wavefunction, the lowest 7 doubly occupied molecular orbitals (MOs) were kept closed, i.e., the $1 \mathrm{~s}$ core orbital of oxygen and the $1 \mathrm{~s}, 2 \mathrm{~s}$, and $2 \mathrm{p}$ core orbitals of sulfur, and the remaining valence orbitals were kept as active. At the CASSCF level of theory, all electronic states with the same spin-multiplicity are averaged together. In the MRCI calculations, we considered all configurations of the CI expansion of the CASSCF wavefunction as a reference. When computing the doublet state, these results lead to more than $1.3 \times 10^{10}\left(6.0 \times 10^{7}\right)$ uncontracted (contracted) configuration state functions (CSFs). Using the $\mathrm{MRCI}+\mathrm{Q}$ wavefunction, the transition dipole moments are evaluated to deduce the radiative lifetimes of the lowest doublet electronic states. These lifetimes ( $\tau$ in $s$ ) are related to the square of the transition dipole moment $\left(|\mu|^{2}\right.$ in Debye) via the following formula:

$$
\tau=6.07706 \times 10^{-6} \sum_{i} 1 /\left|\mu_{i}\right|^{2} \Delta E_{i}^{3},
$$

where $\Delta \mathrm{E}$ is the energy transition in $\mathrm{eV}$ and the sum includes all the doublet states (i) located at lower energy.

At the MRCI+Q level, the HOSO radical is found to be nonplanar with a cis-conformation in good agreement with coupledcluster single double triple $[\mathrm{CCSD}(\mathrm{T})]$-optimized geometries from the literature. ${ }^{20,21}$ At this level of calculation, we predict a torsion angle of $49.7^{\circ}$, which is about $25^{\circ}$ larger than that predicted at the $\operatorname{CCSD}(\mathrm{T})$ level of theory, whereas the remaining geometrical parameters compare very well with previous experimental and theoretical results from the literature (see Fig. 1). ${ }^{1,19-21}$ The trans-HOSO is also optimized (see Table SI), and the barrier to the global minimum is calculated to be $1427.2 \mathrm{~cm}^{-1}$. The barrier to the cis-HOSO conformation is explored and found to be $190 \mathrm{~cm}^{-1}$, which is comparable to that calculated at $\operatorname{CCSD}(\mathrm{T})\left(5 \mathrm{~cm}^{-1}\right) .{ }^{15}$ These results suggest that the HOSO radical is a quasiplanar molecule with a very flat potential along the torsion angle and should exhibit a large amplitude of motion along this coordinate, indicating that the anharmonic effects are very important, as shown in Ref. 20.

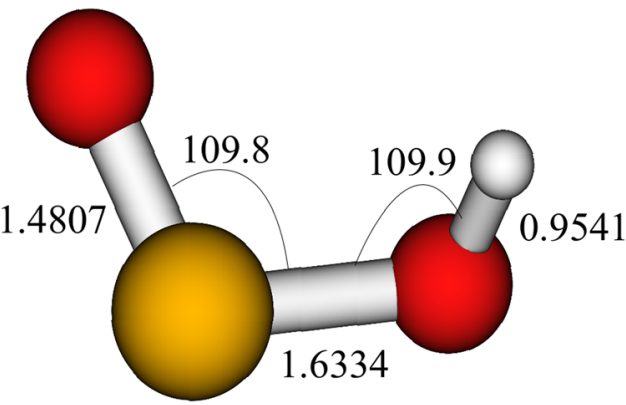

FIG. 1. MRCI+Q/aug-cc-pV $(T+d) Z$ optimized geometry for HOSO. Distances are in angstroms, and angles are in degrees. The dihedral angle was calculated to be $49.7^{\circ}$

Our calculated harmonic vibrational frequencies for both structures are also predicted and presented in Table S1. The vibrational frequencies for the nonplanar structure are all positive, indicating a minimum.

To obtain an initial idea of the lowest doublet states, we start by examining the dominant electron configuration for HOSO. Table I lists the CASSCF/aug-cc-pV $(\mathrm{T}+\mathrm{d}) \mathrm{Z}$ dominant electron configurations of HOSO. Additionally, the transition dipole moments from the ground state to the lowest doublet excited states, the vertical excitation energies, the radiative lifetimes, and the oscillator strength of each transition are presented in the table. These calculations are performed using the equilibrium geometry of HOSO calculated at the $\mathrm{MRCI}+\mathrm{Q} /$ aug-cc-pV $(\mathrm{Q}+\mathrm{d}) \mathrm{Z}$ level of theory.

From Table I, the electronic structure of the ground state may be described as

$$
\begin{gathered}
(0.96)[\text { core }]\left(14 a_{1}\right)^{2}\left(15 a_{1}\right)^{2}\left(16 a_{1}\right)^{2}\left(17 a_{1}\right)^{1} \\
\text { in the } C_{1} \text { symmetry group, }
\end{gathered}
$$

and the core denotes the lowest $\left(13 \mathrm{a}_{1}\right)$ doubly occupied molecular orbitals (MOs). This table shows that the wavefunctions of the electronic states correspond mostly to the promotion of valence electrons from $14 a_{1}, 15 a_{1}$, and $16 a_{1}$ into the $17 a_{1} M O_{S}$, which correspond to $3 \mathrm{a}^{\prime \prime}, 12 \mathrm{a}^{\prime}, 13 \mathrm{a}^{\prime}$ being promoted into the $4 \mathrm{a}^{\prime \prime} \mathrm{MO}_{\mathrm{S}}$ in the Cs symmetry group. Figure 2 shows the evolution of the lowest doublet and quartet electronic states along the torsion angle $\tau$. These potentials are calculated in the $C_{1}$ symmetry group, and the curves are nearly flat along this coordinate. In this calculation, all other

TABLE I. Dominant electron configuration transition dipole moment ( $\mu_{\mathrm{e}}$ in $\left.\mathrm{D}\right)$, oscillator strength (f), radiative lifetime ( $\left.\tau \mu \mathrm{s}\right)$, and vertical excitation energy $\left(T_{v}\right.$ in $\left.\mathrm{eV}\right)$ of the four lowest doublet electronic states of the HOSO radical calculated at the $\mathrm{MRCl}+\mathrm{Q} /$ aug-cc-pV $(\mathrm{Q}+\mathrm{d}) \mathrm{Z}$ level.

\begin{tabular}{llcccc}
\hline \hline States & Dominant electron configuration & $\mathrm{T}_{\mathrm{v}}$ & $\mu_{\mathrm{e}}$ & $\mathrm{f}$ & $\ldots$ \\
\hline $\mathrm{X}^{2} \mathrm{~A}$ & $(0.96)\left(14 \mathrm{a}_{1}\right)^{2}\left(15 \mathrm{a}_{1}\right)^{2}\left(16 \mathrm{a}_{1}\right)^{2}\left(17 \mathrm{a}_{1}\right)^{1}$ & $\ldots$ & $\ldots$ & $\ldots$ & $\ldots$ \\
$\mathrm{A}^{2} \mathrm{~A}$ & $(0.96)\left(14 \mathrm{a}_{1}\right)^{2}\left(15 \mathrm{a}_{1}\right)^{2}\left(16 \mathrm{a}_{1}\right)^{1}\left(17 \mathrm{a}_{1}\right)^{2}$ & 3.63 & 0.40 & 0.0609 & 0.79 \\
$\mathrm{~B}^{2} \mathrm{~A}$ & $(0.78)\left(14 \mathrm{a}_{1}\right)^{2}\left(15 \mathrm{a}_{1}\right)^{1}\left(16 \mathrm{a}_{1}\right)^{2}\left(17 \mathrm{a}_{1}\right)^{2}$ & 4.38 & 0.17 & 0.0130 & 2.46 \\
$\mathrm{C}^{2} \mathrm{~A}$ & $(0.77)\left(14 \mathrm{a}_{1}\right)^{1}\left(15 \mathrm{a}_{1}\right)^{2}\left(16 \mathrm{a}_{1}\right)^{2}\left(17 \mathrm{a}_{1}\right)^{2}$ & 4.97 & 1.03 & 0.5521 & 0.0465 \\
\hline \hline
\end{tabular}




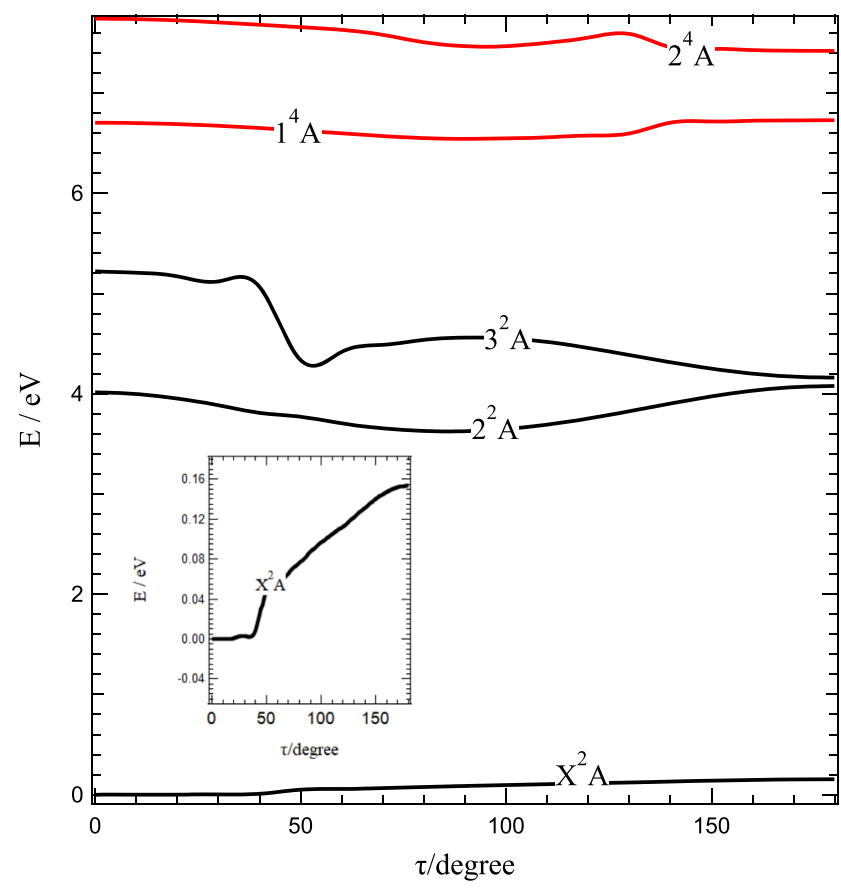

FIG. 2. MRCI+Q/aug-cc-pV $(T+d) Z$ potential energy curves of doublet and quartet states of $\mathrm{HOSO}$ along the torsion angle. The inset corresponds to the potential of the ground state of HOSO.

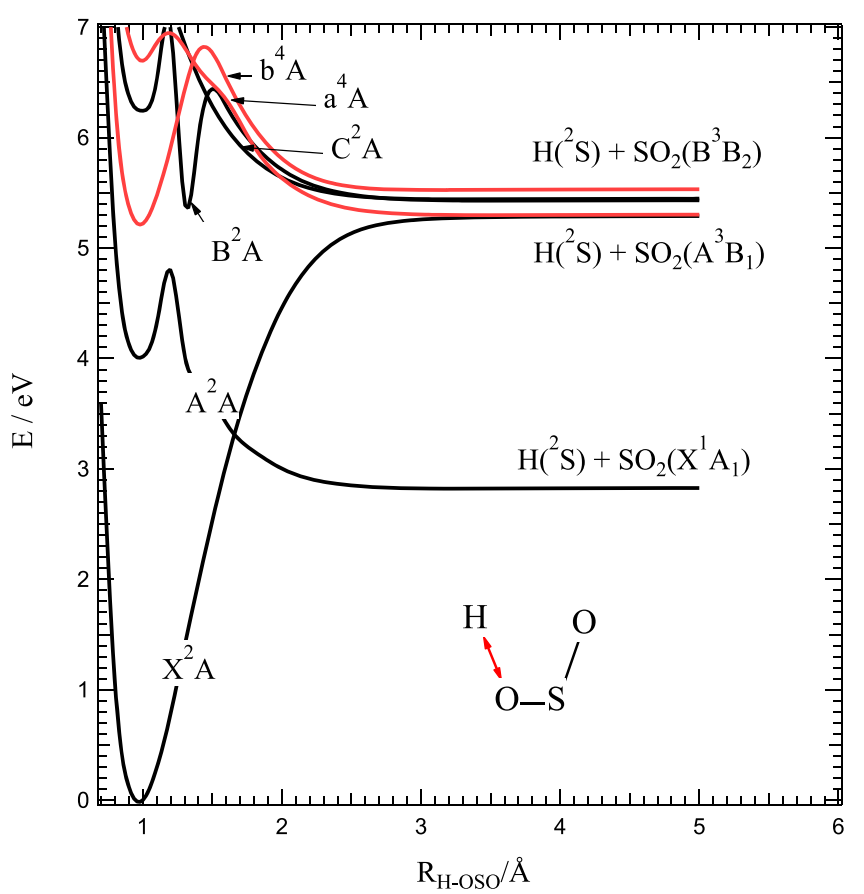

(a) coordinates are kept fixed at their optimized equilibrium geometries, and the $\tau$ angle is varied from $0^{\circ}$ to $180^{\circ}$. This figure (see the inset) shows that the trans conformation has the maximum ground state potential energy surface, which decreases rapidly as the torsion angle decreases from $180^{\circ}$ to $49.7^{\circ}$ and is very flat between 49.7 and 0 .

As the equilibrium geometries of planar and nonplanar HOSO are almost the same and the barrier to planarity is less than $200 \mathrm{~cm}^{-1}$, we fix all coordinates in the planar HOSO structure and change only the HOS and OSO angles to investigate the photoconversion of HOSO. These calculations are performed in the $\mathrm{C}_{s}$ symmetry group and are shown in Fig. S1. This figure shows that all lowest states are bent, and the potentials rapidly increase as the bending angle decreases below $80^{\circ}$.

Figure 3(a) represents the one-dimensional potential energy surface of cis-HOSO as a function of the $\mathrm{H}-\mathrm{O}$ distance, keeping the remaining coordinates fixed at their equilibrium values. This figure shows that the ground state correlates with the second dissociation limit $\mathrm{SO}_{2}\left(\mathrm{~A}^{3} \mathrm{~B}_{1}\right)+\mathrm{H}\left({ }^{2} \mathrm{~S}\right)$. All states present deep potential wells, and their minimum is located above the first dissociation limit, which makes them unstable relative to the $\mathrm{H}-\mathrm{OSO}$ stretch. At $\mathrm{R}_{\mathrm{HO}} \sim 1.3 \AA$, the first and the second electronic states $\mathrm{A}^{2} \mathrm{~A}$ and $\mathrm{B}^{2} \mathrm{~A}$ display an avoided crossing that may play an important role in the production of hydrogen and sulfur dioxide in their ground electronic states. Indeed, the $\mathrm{A}^{2} \mathrm{~A} \leftarrow \mathrm{X}^{2} \mathrm{~A}$ transition can easily occur near $\mathrm{UV}$ due to its relatively large transition dipole moments $(0.40 \mathrm{D})$ and oscillator strength (0.06). If there is absorption into the $\mathrm{A}^{2} \mathrm{~A}$ electronic state, there are two possibilities. If the excitation energy into the $\mathrm{A}^{2} \mathrm{~A}$

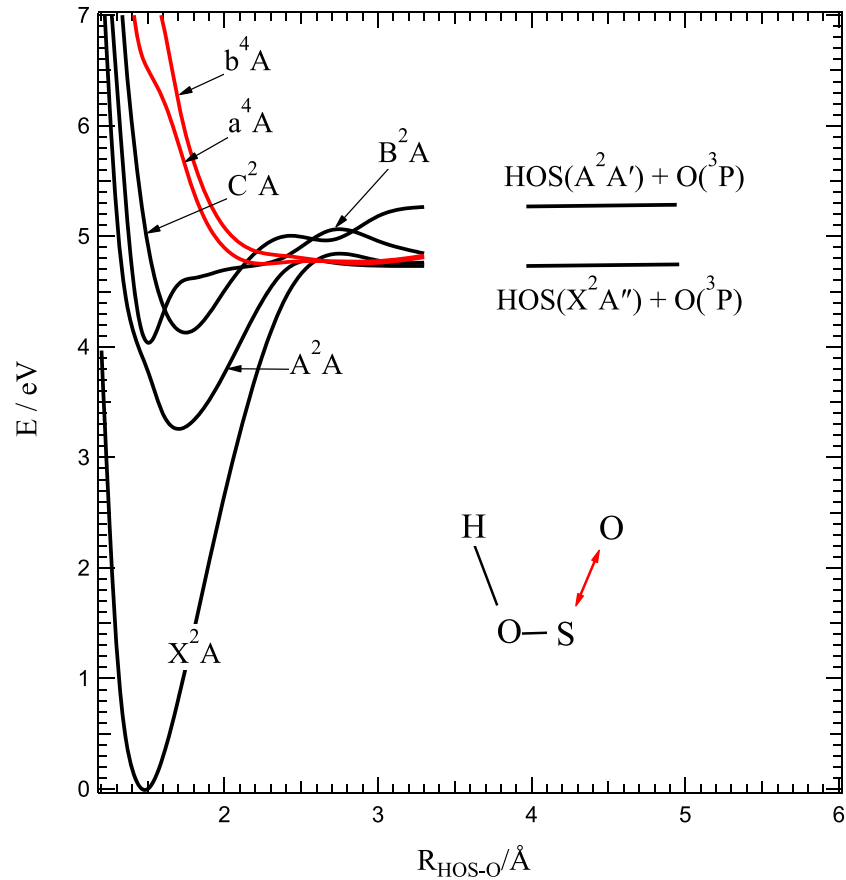

(b)

FIG. 3. MRCl+Q/aug-cc-pV(T+d)Z potential energy curves of the doublet and quartet electronic states of cis-HOSO along the $\mathrm{HO}$ distance [3(a)] and SO distance [3(b)]. 
state is below the barrier for dissociation to $\mathrm{H}\left({ }^{2} \mathrm{~S}\right)+\mathrm{SO}_{2}\left(\mathrm{X}^{1} \mathrm{~A}_{1}\right)$, then there is the possibility of fluorescence back to the ground state. This process will compete with tunneling through the barrier to produce the dissociation products $\mathrm{H}\left({ }^{2} \mathrm{~S}\right)+\mathrm{SO}_{2}\left(\mathrm{X}^{1} \mathrm{~A}_{1}\right)$. Note that cis-HOSO can form through the reaction between $\mathrm{SO}_{2}\left(\mathrm{~A}^{3} \mathrm{~B}_{1}\right)+\mathrm{H}\left({ }^{2} \mathrm{~S}\right)$ in its ground state but cannot form in its excited state because all states are separated by high barriers.

Looking at the PES along the SO bond length [Fig. 3(b)], the minima of the lowest doublet states are located below the $\operatorname{HOS}\left(\mathrm{X}^{2} \mathrm{~A}^{\prime \prime}\right)+\mathrm{O}\left({ }^{3} \mathrm{P}\right)$ asymptote and are characterized by a deep potential, which makes them stable relative to the $\mathrm{HOS}+\mathrm{O}$ dissociation limit. Note that the minimum of the $A^{2} A$ state located at $3.3 \mathrm{eV}$ may be suitable for laser-induced fluorescence detection. The ground state correlates with the first dissociation limit and forms an avoided crossing with the $\mathrm{C}^{2} \mathrm{~A}$ state, which is also the case for $\mathrm{A}^{2} \mathrm{~A}$ and $\mathrm{B}^{2} \mathrm{~A}$ at $\mathrm{R}_{\mathrm{SO}} \sim 2.4 \AA$. These avoided crossings induce a small barrier and prevent the formation of HOSO through the reaction between HOS and $\mathrm{O}$.

Figure 4 displays the one-dimensional cuts of the 3D-PES along the $\mathrm{O}-\mathrm{S}$ stretching coordinate. In these cuts, the remaining coordinates are fixed at the corresponding optimized equilibrium geometry. This figure shows that the ground state correlates with the first dissociation limit $\mathrm{OH}\left(\mathrm{X}^{2} \Pi\right)$ and $\mathrm{SO}\left(\mathrm{X}^{3} \Sigma_{\mathrm{g}}{ }^{-}\right)$. This result shows that cis-HOSO can form in its ground state through the reaction of $\mathrm{OH}$ with $\mathrm{SO}$ in their ground states. All the lowest states are repulsive, except the $\mathrm{B}^{2} \mathrm{~A}$ state, which is characterized by a shallow potential due to the avoided crossing with the $\mathrm{A}^{2} \mathrm{~A}$ electronic state at $\mathrm{R}_{\mathrm{SO}} \sim 1.7$. $\AA$. This state prevents the formation of HOSO in its excited state when one of the fragments is excited.

It is also very interesting to compare the ground electronic state of $\mathrm{HOSO}$ with that of the $\mathrm{HO}_{3}$ radical, both being isoelectronic regarding the valence electrons (19 v.e.). Interestingly, there is no similarity between these two species in their ground state. The $\mathrm{HO}_{3}$ radical is planar, and both cis and trans conformers are minimal on the PESs. ${ }^{32-34}$ Moreover, $\mathrm{HO}_{3}$ is very flat with a binding energy of approximately $0.13 \mathrm{eV}$ relative to the $\mathrm{OH}\left(\mathrm{X}^{2} \Pi\right)+\mathrm{O}_{2}\left(\mathrm{X}^{3} \Sigma^{-}\right)$decomposition products, ${ }^{35-37}$ indicating that it can easily dissociate at relatively low temperatures or via infrared (IR) absorption. For the HOSO radical, as we can see from the above figures, the ground

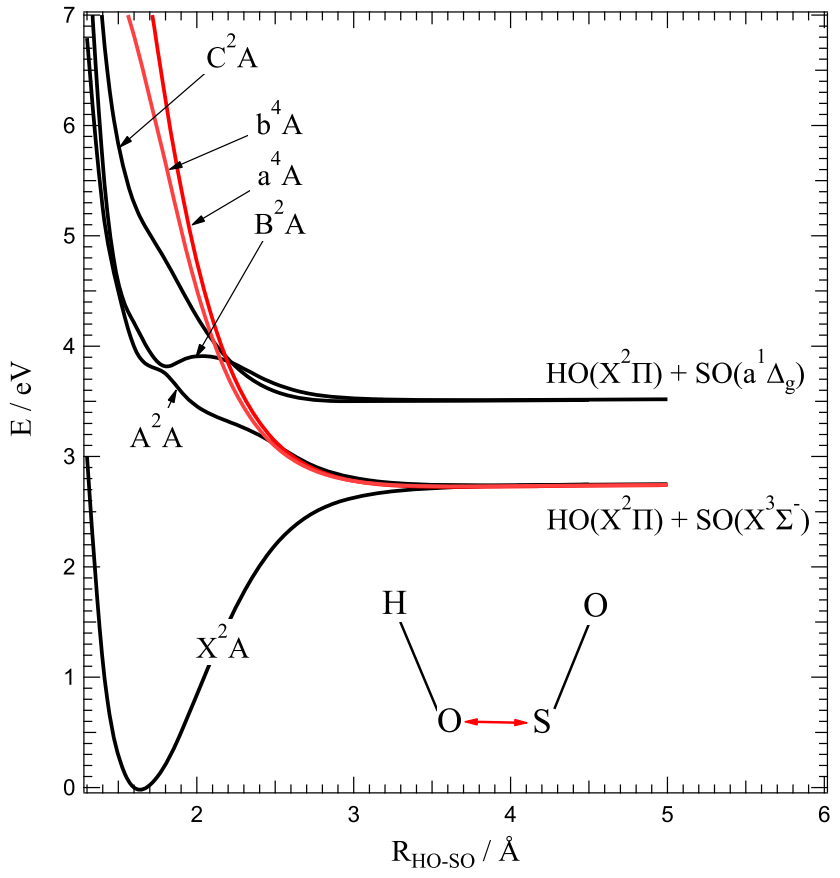

FIG. 4. $M R C l+Q / a u g-c c-p V(T+d) Z$ potential energy curves of the doublet and quartet electronic states of cis-HOSO along the SO distance.

state is stable along the stretching and bending coordinates since the ground state is characterized by a deep potential well located below the first dissociation limit $\mathrm{OH}\left(\mathrm{X}^{2} \Pi\right)+\mathrm{SO}\left(\mathrm{X}^{3} \Sigma_{\mathrm{g}}{ }^{-}\right)$with a predicted binding energy of $2.74 \mathrm{eV}$ at the $\mathrm{MRCI}+\mathrm{Q} /$ aug-cc-pV(T+d)Z level.

In Fig. 5, we summarize the energetic diagram of the lowest dissociation limits of HOSO calculated at the MRCI+Q/aug$\mathrm{cc}-\mathrm{pV}(\mathrm{T}+\mathrm{d}) \mathrm{Z}$ level of theory. In this figure, the reference energy is the energy of HOSO in its ground electronic state. The adiabatic excitation energies of $\mathrm{SO}_{2}$ and $\mathrm{SO}$ are taken from Refs. 38 and 39 .

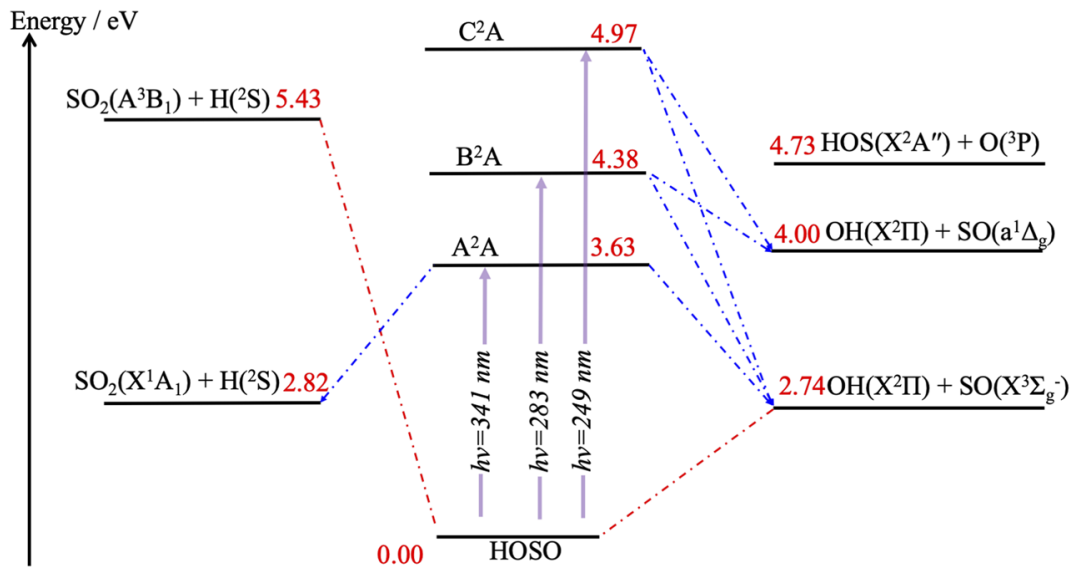

FIG. 5. MRCI+Q energetic diagram and plausible mechanism of the photodissociation of cis-HOSO occurring after UV absorption. 
We optimized the lowest doublet states at the CASSCF $(13,12) /$ aug-cc-pV $(\mathrm{T}+\mathrm{d})$ level. In these calculations, the active space was chosen according to the occupation of the natural orbitals of a previous CI calculation correlating all valence electrons. The results are shown in Table SII. Inspection of the equilibrium geometries of these states reveals that all the SO bond lengths are elongated relative to their values in the ground state, and all the bond lengths differ by less than 0.015 angstroms from the MRCI+Q optimized parameters.

Close inspection of the PESs shown in Figs. 2-4 reveals that photoisomerization to form $\mathrm{HSO}_{2}$ through the excited states upon UV-vis absorption cannot occur. In fact, all states are bent along the bending angle, and there is no repulsive state that allows photoconversion to $\mathrm{HSO}_{2}$ or trans-HOSO (Fig. S2).

According to the transition dipole moments and oscillator strength, the photoexcitation of HOSO in the near UV-vis range (249-369 $\mathrm{nm}$ ) can populate the lowest three electronic states, i.e., $\mathrm{A}^{2} \mathrm{~A}, \mathrm{~B}^{2} \mathrm{~A}$, and $\mathrm{C}^{2} \mathrm{~A}$. These states can lead to the formation of $\mathrm{H}, \mathrm{SO}_{2}$, $\mathrm{OH}$, and $\mathrm{SO}$ in their ground electronic states. Indeed, the $\mathrm{C}^{2} \mathrm{~A}$ state absorbs strongly in the UV region (Fig. 4) since it is characterized by a large transition dipole moment $(1.03 \mathrm{D})$ and oscillator strength (0.55). Absorption to this state may lead to $\mathrm{HO}\left(\mathrm{X}^{2} \Pi\right)$ and $\mathrm{SO}\left(\mathrm{a}^{1} \Delta_{\mathrm{g}}\right)$ with $100 \%$ efficiency. This state crosses the $\mathrm{a}^{4} \mathrm{~A}$ state at Rso $\sim 2.1 \AA$ and the $\mathrm{b}^{4} \mathrm{~A}$ state at $\mathrm{R}_{\mathrm{SO}} \sim 2.2 \AA$, and this crossing favors the formation of $\mathrm{HO}$ and $\mathrm{SO}$ in their ground electronic state via spin-orbit coupling.

Our study reveals that the A and B states are characterized by long lifetimes of 0.79 and $2.46 \mu$ s, respectively. However, they are suitable for laser-induced fluorescence detection. These states may be populated after UV absorption at 369 and $283 \mathrm{~nm}$, respectively, since they are characterized by relatively large transition dipole moments (see Table I). From these excited states, HOSO dissociation to form $\mathrm{SO}_{2}$ and $\mathrm{H}$ or $\mathrm{OH}$ and $\mathrm{SO}$ products in their ground electronic states is likely to occur (Fig. 5). On the other hand, the UV-vis absorption range to photodissociate HOSO is almost the same as that to excite $\mathrm{SO}_{2}$ to the singlet state $(340$ $<\lambda<250 \mathrm{~nm}$ ), which then rapidly relaxes to the triplet state and reacts with water. ${ }^{10}$ This result suggests that the lifetime of HOSO in its ground state may be short and rapid dissociation may occur.

Thus, from the above discussion, we see that there are at least two possible channels [Eqs. (3) and (4)] for the photodissociation of HOSO after UV absorption,

$$
\begin{aligned}
\mathrm{HOSO}+\mathrm{h} v(249-341 \mathrm{~nm}) & \rightarrow \mathrm{OH}+\mathrm{SO}, \\
\mathrm{HOSO}+\mathrm{h} v(341 \mathrm{~nm}) & \rightarrow \mathrm{H}+\mathrm{SO}_{2} .
\end{aligned}
$$

On a fundamental level, the photochemical reaction between $\mathrm{SO}_{2}$ and $\mathrm{H}_{2} \mathrm{O}$ [Eqs. (1) and (2)] may be rewritten either as

$$
\mathrm{SO}_{2}+\mathrm{H}_{2} \mathrm{O} \rightarrow \mathrm{HOSO}+\mathrm{OH} \rightarrow \mathrm{SO}+2 \mathrm{OH}
$$

or

$$
\mathrm{SO}_{2}+\mathrm{H}_{2} \mathrm{O} \rightarrow \mathrm{HOSO}+\mathrm{OH} \rightarrow \mathrm{SO}_{2}+\mathrm{H}+\mathrm{OH} .
$$

The formation of these products ( $\mathrm{SO}, \mathrm{H}$, and $\mathrm{OH}$ ) broadens the chemistry of sulfur dioxide in the Earth's atmosphere, and considering its role is important to obtain a better understanding of the cycle of $\mathrm{SO}_{2}$.
In summary, the present study shows that HOSO is a quasiplanar molecule with a flat potential along the torsion angle in the ground state. This work shows that the photochemistry of the HOSO radical generates $\mathrm{OH}, \mathrm{SO}, \mathrm{H}$, and $\mathrm{SO}_{2}$ in the gas phase, although further experimental and theoretical work will be necessary to determine the branching ratio and production rates. The photodissociation of HOSO in the gas phase has not been previously considered in models devoted to atmospheric studies, and the present work suggests that its role in the chemistry of sulfur dioxide, and more generally in the sulfur chemistry cycle in the Earth's atmosphere, can be significant.

The supplementary material contains the MRCI+Q/aug-cc$\mathrm{pV}(\mathrm{T}+\mathrm{d}) \mathrm{Z}$ PES along the bending angle, the harmonic frequencies of planar and nonplanar HOSO radicals, and the optimized CASSCF geometries for the excited states of HOSO.

\section{REFERENCES}

${ }^{1}$ S. T. Ota and G. L. Richmond, J. Am. Chem. Soc. 134(24), 9967-9977 (2012).

${ }^{2}$ S. Hattori, J. A. Schmidt, M. S. Johnson, S. O. Danielache, A. Yamada, Y. Ueno, and N. Yoshida, Proc. Natl. Acad. Sci. U. S. A. 110(44), 17656-17661 (2013).

${ }^{3}$ M. Sipila, T. Brndt, T. Petaja, D. Brus, J. Vanhanen, F. Stratmann, J. Patokoski, R. L. Mauldin III, A. P. Hyvarinen, H. Lihavainen, and M. Kulmala, Science 327, 1243-1246 (2010).

${ }^{4}$ B. J. Finlayson-Pitts and J. N. Pitts, Jr., Chemistry of the Upper and Lower Atmosphere: Theory, Experiments and Applications (Academic Press, San Diego, CA, 2000), p. 969.

${ }^{5}$ H. Tachikawa, J. Phys. Chem. A 115, 9091-9096 (2011).

${ }^{6}$ J. Zhong, C. Zhu, L. Li, G. L. Richmong, J. S. Francisco, and X. C. Zeng, J. Am. Chem. Soc. 139, 17168-17174 (2017).

${ }^{7}$ M. T. C. Martins-Costa, J. M. Anglada, J. S. Francisco, and M. F. Ruiz-Lopez, J. Am. Chem. Soc. 140, 12341-12344 (2018).

${ }^{8}$ T. E. Dermota, D. P. Hydutsky, N. J. Biamco, and A. W. Castleman, J. Phys. Chem. A 109, 8254-8258 (2005).

${ }^{9}$ F. Dong, S. Heinbuch, J. J. Rocca, and E. R. Bernstein, J. Chem. Phys. 125, 154317 (2006).

${ }^{10}$ J. A. Kroll, B. N. Frandsen, H. G. Kjaergaard, and V. Vaida, J. Phys. Chem. A 122(18), 4465-4469 (2018).

${ }^{11}$ J. M. Anglada, M. T. Martins-Costa, J. S. Francisco, and M. F. Ruiz-López, Phys. Chem. Chem. Phys. 21, 9779 (2019).

${ }^{12}$ B. Wang and H. Hou, Chem. Phys. Lett. 410, 235 (2005).

${ }^{13}$ C. L. Ramussen, P. Glarborg, and P. Marshall, Proc. Combust. Inst. 31, 339 (2007).

${ }^{14}$ M. Wierzejewska and A. Olbert-Majkut, J. Phys. Chem. A 111, 2790-2796 (2007).

${ }^{15}$ M. Y. Ballester and A. J. C. Varandas, Chem. Phys. Lett. 433, 279 (2007).

${ }^{16}$ M. Y. Ballester and A. J. C. Varandas, Phys. Chem. Chem. Phys. 7(11), 23052317 (2005).

${ }^{17}$ B. Napolion and J. D. Watts, Chem. Phys. Lett. 421, 562-565 (2006).

${ }^{18}$ J.-X. Qi, W.-Q. Deng, K.-L. Han, and G. Z. He, J. Chem. Soc., Faraday Trans. 93, 25-28 (1997).

${ }^{19}$ R. C. Fortenberry, J. S. Francisco, and T. J. Lee, J. Phys. Chem. A 121(42), 81088114 (2017).

${ }^{20}$ S. E. Wheeler and H. F. Schaefer III, J. Phys. Chem. A 113(24), 6779-6788 (2009).

${ }^{21}$ M. C. McCarthy, V. Lattanzi, O. Martinez, Jr., J. Gauss, and S. Thorwirth, J. Phys. Chem. Lett. 4(23), 4074-4079 (2013).

${ }^{22}$ E. Isoniemi, L. Khriachtchev, J. Lundell, and M. Rasanen, Phys. Chem. Chem. Phys. 4(9), 1549-1554 (2002). 
${ }^{23}$ T. Trabelsi, S. B. Yaghlane, M. M. Al Mogren, J. S. Francisco, and M. Hochlaf, J. Chem. Phys. 145, 084307 (2016).

${ }^{24}$ T. Trabelsi, M. Kumar, and J. S. Francisco, J. Am. Chem. Soc. 139(43), 1544615449 (2017).

${ }^{25}$ P. J. Knowles and H.-J. Werner, Chem. Phys. Lett. 115, 259 (1985).

${ }^{26}$ H.-J. Werner and P. J. Knowles, J. Chem. Phys. 82, 5053 (1985).

${ }^{27}$ H.-J. Werner and P. J. Knowles, J. Chem. Phys. 89, 5803 (1988).

${ }^{28}$ P. J. Knowles and H.-J. Werner, Chem. Phys. Lett. 145, 514 (1988).

${ }^{29}$ P. G. Szalay and R. J. Bartlett, Chem. Phys. Lett. 214, 481 (1993).

${ }^{30}$ T. H. Dunning, Jr., J. Chem. Phys. 90, 1007 (1989).

${ }^{31}$ D. E. Woon and T. H. Dunning, Jr., J. Chem. Phys. 98, 1358 (1993).

${ }^{32}$ K. Suma, Y. Sumiyoshi, and Y. Endo, Science 308(5730), 1885-1886 (2005).
${ }^{33}$ A. Mansergas, J. M. Anglada, S. Olivella, M. F. Ruiz-López, and M. MartinsCosta, Phys. Chem. Chem. Phys. 9(44), 5865-5873 (2007).

${ }^{34}$ L. P. Viegas, D. Carolina, and A. J. Varandas, Chem. Phys. Lett. 620, 61-66 (2015).

${ }^{35}$ S. D. Le Picard, M. Tizniti, A. Canosa, I. R. Sims, and I. W. Smith, Science 328(5983), 1258-1262 (2010).

${ }^{36}$ J. M. Anglada, S. Olivella, and A. Solé, J. Chem. Theory Comput. 6(9), 27432750 (2010).

${ }^{37}$ A. J. C. Varandas, Phys. Chem. Chem. Phys. 13(34), 15619-15623 (2011).

${ }^{38}$ M. H. Palmer, D. A. Shaw, and M. F. Guest, Mol. Phys. 103(6-8), 1183-1200 (2005).

${ }^{39}$ S. Saito, J. Chem. Phys. 53(6), 2544-2545 (1970). 